\title{
Tissue Expression Profiles of 5 Putative Imprinted Genes in Bovine Chromosome 29
}

\author{
Oladeji Bamidele1,2*, Ofelia G. Omitogun1, Ikhide G. Imumorin ${ }^{2 *}$ \\ ${ }^{1}$ Biotechnology Laboratory, Department of Animal Sciences, Obafemi Awolowo University, Ile-Ife, Nigeria \\ ${ }^{2}$ Animal Genetics and Genomics Laboratory, International Programs, College of Agriculture and Life Sciences, Cornell University, \\ Ithaca, NY, USA \\ Email: ^bamideledeji@gmail.com, ^igi2@cornell.edu
}

How to cite this paper: Bamidele, O., Omitogun, O.G. and Imumorin, I.G. (2016) Tissue Expression Profiles of 5 Putative Imprinted Genes in Bovine Chromosome 29. Open Journal of Animal Sciences, 6, 289-297.

http://dx.doi.org/10.4236/ojas.2016.64033

Received: August 3, 2016

Accepted: October 8, 2016

Published: October 11, 2016

Copyright $\odot 2016$ by authors and Scientific Research Publishing Inc. This work is licensed under the Creative Commons Attribution International License (CC BY 4.0).

http://creativecommons.org/licenses/by/4.0/

\begin{abstract}
Genomic imprinting is an epigenetic process that regulates gene expression in the mammalian genome. Although there are specific imprinting differences between the mammalian species, cattle present unique opportunity for characterizing imprinted genes because of its sub-species classification. Five putative imprinted genes (TSSC4, CDKN1C, KCNQ1, PHLDA2 and NAP1L4) on bovine chromosome 29 (Bta 29) which had been characterized to have promoter CGI were quantitatively assayed for their relative expression across eight tissues (muscle, brain, liver, kidney, spinal cord, heart, lymph and skin) sampled in Angus cattle. The differential abundance of these genes in muscle and skin tissues of Angus, White Fulani and N'Dama cattle breeds was comparatively analyzed. These three breeds are representative of the Bos taurus and Bos indicus cattle sub-species while the two tissues are selected based on their strategic economic importance in cattle production. All the genes, except TSSC4, were relatively expressed across all the tissues. It was observed that Angus had the highest differential abundance in muscle tissues for TSSC4, PHLDA2 and NAP1L4 while N'Dama and White Fulani were the most abundant for KCNQ1 and NAP1L4 in skin tissues. The study identified marked differences in the expression profiles of the genes in both muscle and skin tissues of the three breeds that were characteristics of their genetics, environment and nutrition.
\end{abstract}

\section{Keywords}

Imprinted Genes, Bovine, Angus, White Fulani, N’Dama

\section{Introduction}

The molecular characterization of imprinted genes is intricately linked to the quantifi- 
cation of DNA methylation (DNAm) patterns [1] and analysis of messenger RNA (mRNA) levels (i.e. gene expression). In addition to the unique expression patterns of imprinted genes, their relative abundance and mRNA levels have been reported to be of significance to genomic imprinting [2]. In a previous study conducted on the sequence characteristics of some putative imprinted genes on bovine chromosome 29, Bamidele et al. [3] had identified 5 genes for further experimental analysis. These genes were TSSC4, CDKN1C, KCNQ1, PHLDA and NAP1L4. In the current study, we carried out gene expression analysis in selected tissues of the Angus, White Fulani and N'Dama cattle breeds. Although the sequenced genome (i.e. reference sequence) of the Hereford cow is representative of both the Bos primigenius taurus and Bos primigenius indicus sub-species of cattle [4], there are increasing indications of sub-species differences in the bovine genomic architecture that may influence the identification and expression of imprinted genes in cattle. The Bos primigenius taurus (i.e. Bos taurus) commonly referred to as "taurine" cattle are the humpless breeds (e.g. Angus, Hereford) primarily found in temperate regions which also include the similar tropically adapted types (e.g. N'Dama). While, the Bos primigenius indicus (i.e. Bos indicus) are the "Zebu" cattle breeds (e.g. White Fulani, Brahman) well adapted to withstand high temperature conditions and characterized by a fatty hump, drooping ears and a large pendulous dewlap [5]. Hence, this study aims to investigate the total RNA levels of these putative imprinted genes and also compare their differential abundance between and within the two cattle sub-species. This will further facilitate the characterization of the identified putative imprinted genes in cattle.

\section{Materials and Method}

\subsection{Animal}

Eight different tissue samples (muscle, brain, liver, kidney, lymph node, spinal cord, heart and skin) of two adult Angus cattle were sampled while only the muscle and skin tissues of both the White Fulani and N'Dama (two biological replicates each) tropical cattle breeds were obtained. All the tissue samples were stored in the $-80^{\circ} \mathrm{C}$ freezer. All the sampled cattle breeds were bulls.

\subsection{Total RNA Isolation}

Total RNA was extracted from the tissues using the RNeasy kit (QIAGEN). The extracted RNA was treated with RNase-free DNase to remove any possible contaminating genomic DNA. Samples with optical density values between $1.7-1.8$ (260/280) and 1.9 - $2.0(260 / 230)$ as well as a minimum concentration of $100 \mathrm{ng} / \mu \mathrm{l}$ were selected as templates for gene expression analysis.

\subsection{Quantitative Real-Time PCR Analysis}

The qRT-PCR approach used by Zaitoun and Khatib [6] was adapted. A two-step realtime $\mathrm{qPCR}$ protocol was performed using the iScript ${ }^{\mathrm{TM}}$ reverse transcription supermix to first reverse transcribe the extracted total RNA into cDNA. The resulting cDNA was 
then used as the template for the $\mathrm{qPCR}$ reactions using the SYBR green qPCR master mix kit. Primers were designed from the mRNA reference sequences (NCBI) using the Primer 3v. 0.4.0 [7] [8] and ordered from Integrated DNA Technologies (IDT), CA, USA. The qPCR primers were designed for each of the genes (Table 1). All the primers were reconstituted to $10 \mu \mathrm{M}$ concentration and optimized at $60^{\circ} \mathrm{C}$ by performing a standard PCR with the cDNA as the template. Although two housekeeping genes (Succinate dehydrogenase complex, subunit A (SDHA) and Glyceraldehyde-3-phosphate dehydrogenase (GADPH)) were tested to be used as reference genes for the normalization, however, GADPH was selected because its expression was more stable. The comparative CT method for relative quantification was performed for the real time qPCR analysis with liver as the calibrator [9]. The reactions were performed on the $\mathrm{ViiA}^{\mathrm{TM}} 7$ Real-Time PCR System (APPLIED BIOSYSTEMS) and the generated CT values were analyzed using the Livak or $2^{-\triangle \Delta C T}$ method [10]. The differential abundance of the gene expression levels between the breeds were statistically analyzed using both the independent t-test of SPSS11.0 software and the Wilcoxon test of SAS 9.1 software.

\section{Results}

The normalized relative expression levels of the five genes are presented in Table 2. All the genes were expressed in all the eight tissues except for TSSC4, which was not expressed in skin. The abundance of each of the genes varied across all the tissues. TSSC4, PHLDA2 and NAP1L4 were most abundant in muscle while CDKN1C and KCNQ1 were most expressed in skin and brain respectively. For TSSC4 and KCNQ1 all tissues were down-regulated except muscle $(282.1)$ and brain $(34,492.6)$ respectively. The relative expression of CDKN1C was only upregulated in lymph (1.2) and skin tissues (2.2). For PHLDA2, the transcript was upregulated in all the tissues except in heart (0.1)

Table 1. Primers for the qPCR assays.

\begin{tabular}{|c|c|c|c|}
\hline Gene & Primer Pair $\left(5^{\prime}-3^{\prime}\right)$ & Product (bps) & $\begin{array}{c}\text { mRNA Reference } \\
\text { Sequence No. }\end{array}$ \\
\hline TSSC4 & $\begin{array}{l}\text { TGTCTTCACCAAACCCACCC } \\
\text { CACTCCACTCCTCGGCTTC }\end{array}$ & 179 & NM_001075410.1 \\
\hline KCNQ1 & $\begin{array}{c}\text { CTCGCTCATCCAGACGGCCT } \\
\text { GGCTCACCCCGTTGTCCTTATCC }\end{array}$ & 182 & NM_001205441.1 \\
\hline CDKN1C & $\begin{array}{l}\text { GCACCTTTCCCATGATCGC } \\
\text { GGAAGTTGTAGTCCCAGCGA }\end{array}$ & 141 & NM_001077903.2 \\
\hline PHLDA2 & $\begin{array}{l}\text { ACCCAATTGCTGACCAGGG } \\
\text { CACAGCGGACTCTGGAGGCT }\end{array}$ & 101 & NM_001076521.2 \\
\hline NAP1L4 & $\begin{array}{l}\text { GTTCACGTTAGCCTCCGACT } \\
\text { ATCTCGGCATCATCGTCGTC }\end{array}$ & 183 & NM_001038094.2 \\
\hline SDHA & $\begin{array}{l}\text { GCAGAACCTGATGCTTTGTG } \\
\text { CGTAGGAGAGCGTGTGCTT }\end{array}$ & 185 & NM_005221657.1 \\
\hline GADPH & $\begin{array}{l}\text { CCTGCCCGTTCGACAGATA } \\
\text { GGCGACGATGTCCACTTTG }\end{array}$ & 150 & NM_001034034.1 \\
\hline
\end{tabular}


Table 2. Relative quantification of the 5 gene expressions.

\begin{tabular}{|c|c|c|c|c|c|c|}
\hline \multirow{2}{*}{ Breed } & \multirow{2}{*}{ Tissue } & \multicolumn{5}{|c|}{ Fold Change $2^{-\Delta \Delta C T}$} \\
\hline & & TSSC4 & KCNQ1 & CDKN1C & PHLDA2 & NAP1L4 \\
\hline \multirow[t]{8}{*}{ Angus } & Muscle & 282.08 & 0.03 & 0.51 & 23.75 & 76.11 \\
\hline & Brain & 0.17 & $34,492.60$ & 0.60 & 3.66 & 22.20 \\
\hline & Liver & 1.00 & 1.00 & 1.00 & 1.00 & 1.00 \\
\hline & Kidney & 0.26 & 0.50 & 0.81 & 16.00 & 0.68 \\
\hline & Spinal cord & 0.03 & 0.01 & 0.42 & 1.52 & 0.12 \\
\hline & Heart & 0.18 & 0.50 & 0.08 & 0.11 & 0.32 \\
\hline & Lymph & 0.49 & 0.10 & 1.26 & 5.82 & 0.39 \\
\hline & Skin & - & 0.39 & 2.20 & 12.73 & 0.56 \\
\hline \multirow[t]{2}{*}{ White Fulani } & Muscle & 0.09 & 0.15 & 0.84 & 6.08 & 13.36 \\
\hline & Skin & - & 0.49 & 1.00 & 11.35 & 30.69 \\
\hline \multirow[t]{2}{*}{ N'Dama } & Muscle & 0.16 & 0.55 & 1.23 & 4.82 & 33.82 \\
\hline & Skin & - & 0.18 & 1.23 & 4.93 & 18.00 \\
\hline
\end{tabular}

while in NAP1L4, only muscle (76.1) and brain (22.2) tissues were upregulated. The gene expression levels across Angus, White Fulani and N'Dama for muscle and skin tissues are represented in Figure 1 and Figure 2. The results show significant differences ( $\alpha=0.05,0.01 \& 0.001)$ in the pairwise comparisons between the breeds. Angus had the highest gene expression levels for TSSC4 (282.1), PHLDA2 (23.8) and NAP1L4 (76.1) in muscle than N'Dama and White Fulani, however its fold change for NAP1L4 in skin was the lowest amongst the three breeds. N'Dama had the highest gene expression levels in muscle for both CDKN1C (1.23) and KCNQ1 (0.55). The fold difference for White Fulani was found to be the highest in skin tissues only for KCNQ1 and NAP1L4 while it had the lowest levels of gene expression for muscle in both TSSC4 and NAP1L4 as well as in skin for CDKN1C. Comparing the pattern of expression of PHLDA2 across the three cattle breeds was similar in both muscle and skin tissues (i.e. Angus $>$ White Fulani $>$ N’Dama).

\section{Discussion}

The relative quantitation of the transcription levels of each of the five genes earlier predicted to have promoter CGIs was investigated according to the histological and physiological tissues systems. According to the GeneCards database [11] these tissue systems can be classified as: skeletal (muscle), nervous (brain, spinal cord), internal (liver and kidney), cardiac (heart), immune (lymph) and secretory/integumentary (skin) systems. The microarray, RNASeq and serial analysis of gene expression (SAGE) using adult human samples had shown that TSSC4, CDKN1C, KCNQ1 and PHLDA2 are expressed in almost all tissues with the exception of NAP1L4 which is ubiquitous [12]. This is consistent with the qPCR results of this study. Our findings support the hypothesis that 

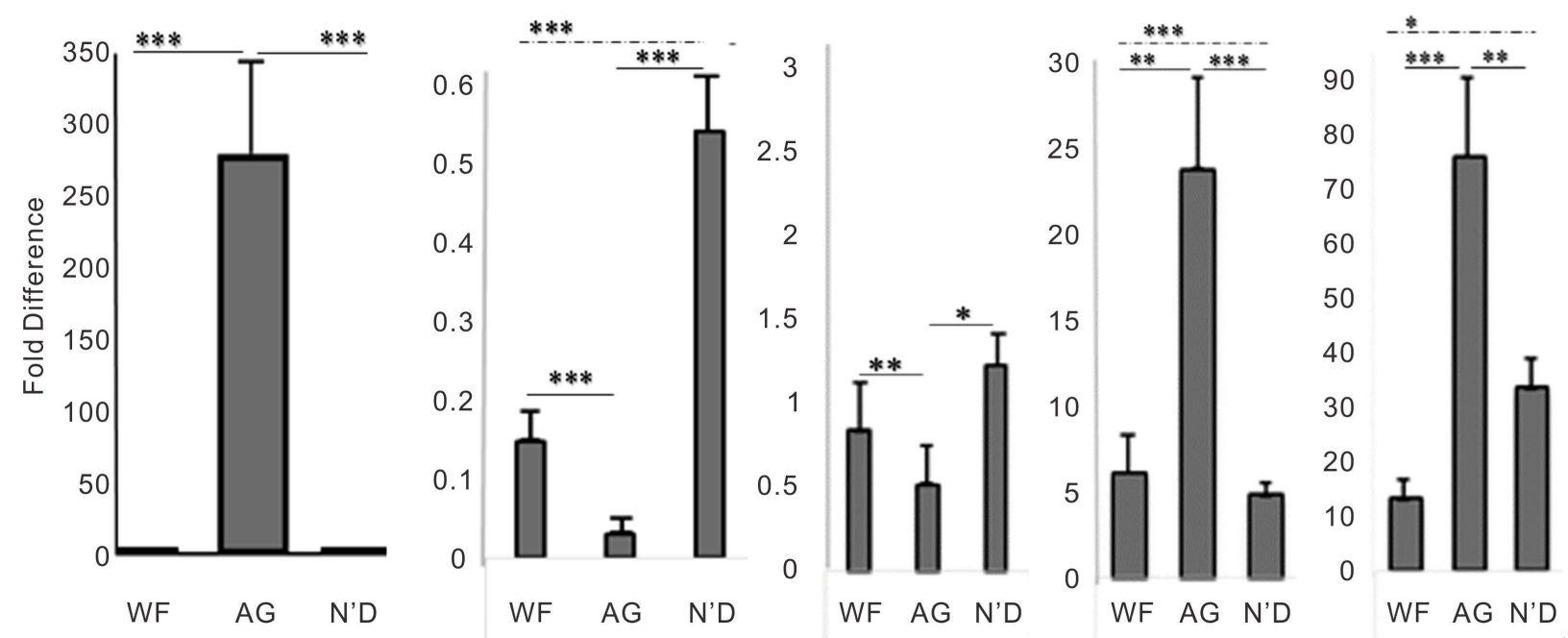

Figure 1. The respective differential abundance of TSSC4, KCNQ1, CDKN1C, PHLDA2 and NAP1L4 in the skin tissue of AG (Angus), WF (White Fulani) and N'D (N’Dama) cattle breeds. The corresponding levels of significance are indicated as: ${ }^{* * *} \mathrm{P}<$ $0.001,{ }^{* *} \mathrm{P}<0.01,{ }^{*} \mathrm{P}<0.05$.
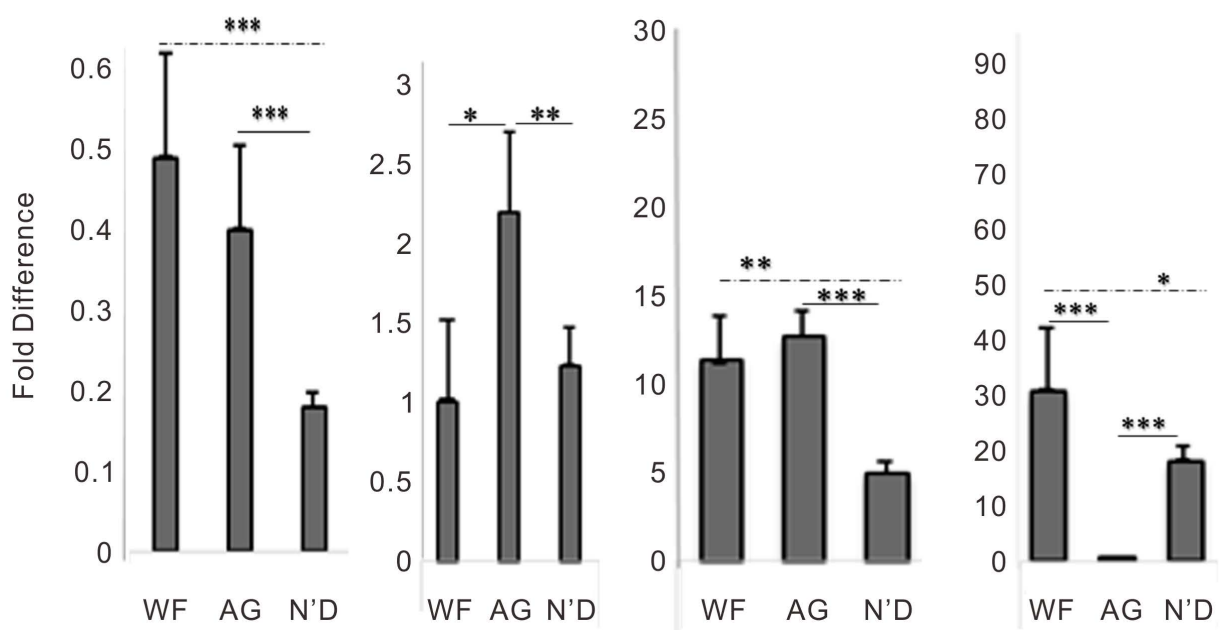

Figure 2. The respective differential abundance of KCNQ1, CDKN1C, PHLDA2 and NAP1L4 in the skin tissue of AG (Angus), WF (White Fulani) and N'D (N'Dama) cattle breeds. The corresponding levels of significance are indicated as: ${ }^{* *} \mathrm{P}<0.001,{ }^{* *} \mathrm{P}<0.01,{ }^{*} \mathrm{P}<0.05$.

promoter CGIs are required for most cellular function as such are present in ubiquitous genes [13]. All the five genes predicted to have promoter CGIs were expressed in all the eight tissues except TSSC4. According to Yamashita et al. [14], this suggests that promoter CGIs are correlated with the expression specificity of genes as such can be used as markers in the mammalian genome.

It was observed in this study that TSSC4 was unexpressed in the assayed skin tissues. In a related study by Zaitoun and Khatib [6], the expression of TSSC4 was reported in sixteen fetal and adult bovine tissues with the exception of the skin tissue. In addition, the neXtProt database [15] also showed that TSSC4 is not expressed in both the epidermis and dermis human skin layers. This is consistent with the result of this study 
wherein TSSC4 was not expressed in the skin tissues of the three cattle breeds. However, it may also mean that the putative imprinted TSSC4 gene had been switched off in the skin tissues of the respective developmental stages investigated by this study as well as other previous studies. According to Imumorin et al. [16] this may be due to the fact that epigenetic mechanisms regulating genomic imprinting could be influenced by the prevailing developmental stage of the animal.

When compared across all the tissues for each of the genes, the transcription levels were highest in muscle (TSSC4, PHLDA2 and NAP1L4), brain (KCNQ1) and skin (CDKN1C). This is consistent with the associated molecular functions of the respective genes [17]. The presence of the protein kinases (cAMP, PKC, CK2) involved in glycogen regulation, muscle development and cellular regulation earlier reported by Bamidele et al. [3] to be found in TSSC4, PHLDA2 and NAP1L4, could also explain the up-regulation of the respective gene transcripts in the muscle tissue system. This is in contrast to that observed in KCNQ1 and CDKN1C wherein no protein kinases were earlier found and whose transcripts were only upregulated in the nervous and secretory tissue systems respectively.

The differential abundance of the five genes was investigated and compared in the muscle and skin tissues of the three cattle breeds. These two tissues were selected based on the knowledge of their strategic importance in livestock production. According to Lawrie and Ledward [18], meat quality is indicative of the type of nutrition, environment, genetics and other management practices. Moreover, cattle breeding has over the years focused on the selection for improved growth, meat and carcass traits. This implies that gene expression levels in muscle tissues may highlight the differences and similarities in animal husbandry across various production systems, climate and breeds. Also, skin tissue was selected because of its characteristic morphological distinctiveness as well as its physiological role as the animal's first line of defense against external or environmental stimuli. It was observed that Angus had the highest differential abundance in muscle tissues for TSSC4, PHLDA2 and NAP1L4 amongst the three breeds. This suggests that the years of intensive breeding programmes for the Angus beef cattle may have increased the selective pressure on these growth-related genes which may have accounted for its improved performance in terms of the high feed conversion ratio than that obtained in White Fulani or N'Dama [19] [20].

On the other hand, the N'Dama which is also a taurine cattle breed raised principally for beef production recorded the highest differential abundance in muscle for CDKN1C and KCNQ1. In view of this, this result suggests that the five putative imprinted genes are significantly associated with meat production in the beef cattle (Angus and N'Dama). The observed difference in the gene expression profile of the muscle tissues between the two Bos taurus breeds (Angus and N'Dama) can be that due to breeding and nutrition. Also, the temperate environment in which Angus is being raised has proven to be of benefit to its genetic improvement unlike the N'Dama which is primarily raised under an extensive/nomadic system of the Sub-Saharan Africa.

The muscle expression profile of the White Fulani (Bos indicus) cattle which is pri- 
marily raised as a dual purpose breed (beef and dairy) showed an intermediate differential abundance between that obtained in Angus and N'Dama. This pattern was observed in CDKN1C, KCNQ1 and PHLDA2. This may be indicative of its dual purpose function.

Our results show that White Fulani had the highest differential abundance in skin amongst the three breeds for KCNQ1 and NAP1L4 and that the abundance varied with respect to the breeds' skin colours. This suggests that these two genes may be positively associated with the pigmentation differences of White Fulani, N'Dama and Angus. According to Slominski et al. [21], the mammalian skin pigmentation system (Melanogenesis) is under a complex regulatory control of multiple agents interacting via pathways activated by receptor-dependent and independent mechanisms. Although the $\mathrm{MC} 1$ receptor is the most positive regulator of melanogenesis, other regulators such as transcription factors (Brn2, TBX2, PAX3 and SOX) and protein kinases (cAMP, PKC, CK2) have also been reported to be actively involved in the complex regulatory system [21]-[23]. Two of these regulators (SOX and CK2) have been reportedly identified in NAP1L4 gene [3] which according to Busca and Balotti [22], play a significant role in the regulation of melanogenesis. Several studies in human and mice have reported that the inhibition of the CK2 is specifically linked to variations in skin pigmentations [24] [25]. This may have contributed to the pigmentation differences observed in the three breeds. With respect to the KCNQ1 gene, its importance in melanogenesis may be seen in the primary function of its ion transport protein sub family which controls the exchange of ions during various cellular activities. According to Kondo and Hearing [26], the significance of KCNQ1 is in its ion transport and transfer processes (ion transport protein sub family) which are critical elements in the distribution of melanin pigments. In view of this, the differential abundance of the KCNQ1 gene suggests a variation in its intracellular ion transport or exchange during melanin and eumelanin synthesis for the respective skin pigmentations of White Fulani, Angus and N'Dama cattle breeds. The high differential abundance of NAP1L4 and KCNQ1 in the skin tissues of White Fulani and their respective significance in melanogenesis may also lend credence to the characteristic feature of the zebu cattle (Bos indicus) as a thermo-tolerant breed [27].

\section{Conclusion}

This study showed that the five putative growth-related imprinted genes were relatively expressed in all the eight tissues of the adult cattle (muscle, brain, liver, kidney, heart, spinal cord, lymph and skin) except for TSSC4 gene which was unexpressed in the skin tissue. This study provides insight into the differential abundance of each of the five genes in muscle and skin tissues amongst the three cattle breeds. The gene expression patterns suggest the triad influence of genetics, epigenetics and nutrition on the breed characteristics of Angus, White Fulani and N'Dama which may be used to further characterize the breeds along their production types (beef or dairy), immune system (trypano-tolerance) and skin pigmentation (white, brown or black). The regulatory roles of the SOX transcription factor and CK2 protein kinase in NAP1L4 may be further inves- 
tigated as biomarkers in understanding thermo-tolerance.

\section{Acknowledgements}

We are thankful for the collaboration between the Obafemi Awolowo University, Ile-Ife and Cornell University, Ithaca which provided visiting scholarship to the first author as well as the financial support by the College of Agriculture and Life Sciences, Cornell University, and Zoetis, Inc. Additional support by National Research Initiative Competitive Grant Program (Grant No. 2006-35205-16864) from the USDA National Institute of Food and Agriculture; USDA-NIFA Research Agreements (Nos. 2009-6520505635, 2010-34444-20729) and USDA Federal formula Hatch funds appropriated to the Cornell University Agricultural Experiment Station are gratefully acknowledged.

\section{References}

[1] Bird, A. (2002) DNA Methylation Patterns and Epigenetic Memory. Genes Development, 16, 6-21. http://dx.doi.org/10.1101/gad.947102

[2] Jiang, Z.L., Dong, H., Zheng, X.B., Marjani, S.L., Donovan, D.M., Chen, J.B. and Tian, X.C. (2015) mRNA Levels of Imprinted Genes in Bovine in Vivo Oocytes, Embryos and Cross Species Comparisons with Humans, Mice and Pigs. Scientific Reports, 5, Article Number: 17898. http://dx.doi.org/10.1038/srep17898

[3] Bamidele, O., Omitogun, O.G. and Imumorin, I.G. (2015) DNA Sequence Characteristics and Phylogenetics of Putative Imprinted Genes on Bovine Chromosome 29. Journal of Agricultural Sciences, 7, 131-142. http://dx.doi.org/10.5539/jas.v7n8p131

[4] Elsik, C.G., Tellam, R.L., Worley, K.C., Gibbs, R.A., Muzny, D.M., Weinstock, G.M., Andelson, D.L., and the Bovine Genome Sequencing and Analysis Consortium (2009) The Genome Sequence of Taurine Cattle: A Window to Ruminant Biology and Evolution. Science, 324, 522-528. http://dx.doi.org/10.1126/science.1169588

[5] Payne, W.J.A. and Wilson, R.T. (1999) An Introduction to Animal Husbandry in the Tropics. 5th Edition, Blackwell Science, Oxford, 177-221.

[6] Zaitoun, I. and Khatib, H. (2008) Comparative Genomic Imprinting and Expression Analysis of Six Cattle Genes. Journal of Animal Science, 86, 25-32.

http://dx.doi.org/10.2527/jas.2007-0150

[7] Untergrasser, A., Cutcutache, I., Koressaar, T., Ye, J., Faircloth, B.C., Remm, M. and Rozen, S.G. (2012) Primer3-New Capabilities and Interfaces. Nucleic Acids Research, 40, e115. http://dx.doi.org/10.1093/nar/gks596

[8] Koressaar, T. and Remm, M. (2007) Enhancements and Modifications of Primer Design Program Primer3. Bioinformatics, 23, 1289-1291. http://dx.doi.org/10.1093/bioinformatics/btm091

[9] Applied Biosystems (2008) Guide to Performing Relative Quantitation of Gene Expression Using Real-Time Quantitative PCR. Review Biology, Part Number 4371095.

[10] Livak, K.J. and Schmittgen, T.D. (2001) Analysis of Relative Gene Expression Data Using Real-Time Quantitative PCR and the $2^{-\Delta \Delta \mathrm{CT}}$ Method. Methods, 25, 402-408. http://dx.doi.org/10.1006/meth.2001.1262

[11] Genecards Database. http://www.genecards.org

[12] Rebhan, M., Chalifa-Caspi, V., Prilusky, J. and Lancet, D. (1997) GeneCards: Integrating Information about Genes, Proteins and Diseases. Trends in Genetics, 13, 163. 
http://dx.doi.org/10.1016/S0168-9525(97)01103-7

[13] Antequera, F. (2003) Structure, Function and Evolution of CpG Island Promoters. Cell and Molecular Life Science, 60, 1647-1658.

[14] Yamashita, R., Suzuki, Y., Sugano, S. and Nakai, K. (2005) Genome-Wide Analysis Reveals Strong Correlation between CpG Islands with Nearby Transcription Start Site of Genes and Tissue Specificity. Gene, 350, 129-136. http://dx.doi.org/10.1016/j.gene.2005.01.012

[15] Nextprot Database. http://nextprot.org/

[16] Imumorin, I.G., Peters, S.O. and De Donato, M. (2012) Genomic Imprinting and Imprinted Gene Clusters in the Bovine Genome. In: Khatib, H., Ed., Livestock Epigenetics, Wiley-Blackwell, Hoboken, 89-112.

[17] Gene Ontology. http://geneontology.org/page/go-database

[18] Lawrie, R.A. and Ledward, D.A. (2006) Lawrie's Meat Science. 6th Edition, Woodhead, Cambridge, 11-30. http://dx.doi.org/10.1533/9781845691615

[19] The American Angus Association. http://angus.org

[20] Tawa, C.L. and Rege J.E.O. (1996) White Fulani Cattle of West and Central Africa. Animal Genetic Resources Information Bulletin, 11, 137-158. http://dx.doi.org/10.1017/s101423390000064x

[21] Slominski, A., Tobin, D.J., Shibahara, S. and Wortsman, J. (2004) Melanin Pigmentation in Mammalian Skin and Its Hormonal Regulation. Physiological Reviews, 84, 1155-228. http://dx.doi.org/10.1152/physrev.00044.2003

[22] Busca, R. and Ballotti, R. (2000) Cyclic AMP a Key Messenger in the Regulation of Skin Pigmentation. Pigment Cell Research, 13, 60-69. http://dx.doi.org/10.1034/j.1600-0749.2000.130203.x

[23] Milenkovic, T., Memisevic, V., Ganesan, A.K. and Przulj, N. (2010) Systems-Level Cancer Gene Identification from Protein Interaction Network Topology Applied to Melanogenesis-Related Functional Genomics Data. Journal of Royal Society Interface, 7, 423-437. http://dx.doi.org/10.1098/rsif.2009.0192

[24] Olgen, S., Gotz, C. and Jose, J. (2007) Synthesis and Biological Evaluation of 3-(SubstitutedBenzylidene)-1, 3-Dihydro-Indolin Derivatives as Human Protein Kinase CK2 and p60-Src Tyrosine Kinase Inhibitors. Biological and Pharmaceutical Bulletin, 30, 715-718. http://dx.doi.org/10.1248/bpb.30.715

[25] Thanigaimalai, P., Lee, K., Sharma, V.K., Sharma, N., Roh, E., Kin, Y. and Jung, S. (2011) Identification of Indoline-2-Thione Analogs as Novel Potent Inhibitors of $\alpha$-Melanocyte Stimulating Hormone Induced Melanogenesis. Chemical and Pharmaceutical Bulletin, 59, 1285-1288. http://dx.doi.org/10.1248/cpb.59.1285

[26] Kondo, T. and Hearing, V.J. (2011) Update on the Regulation of Mammalian Melanocyte Function and Skin Pigmentation. Expert Review Dermatology, 6, 97-108. http://dx.doi.org/10.1586/edm.10.70

[27] Collier, R.J., Collier, J.L., Rhoads, R.P. and Baumgard, L.H. (2008) Genes Involved in the Bovine Heat Stress Response. Journal of Dairy Science, 91, 445-454.

http://dx.doi.org/10.3168/jds.2007-0540 